\title{
The effect of diabetes mellitus on patients undergoing coronary surgery: A risk-adjusted analysis
}

Chanaka Rajakaruna, MRCS, Chris A. Rogers, PhD, Chinthaki Suranimala, MRCS, Gianni D. Angelini, MD, FRCS, and Raimondo Ascione, MD, FRCS

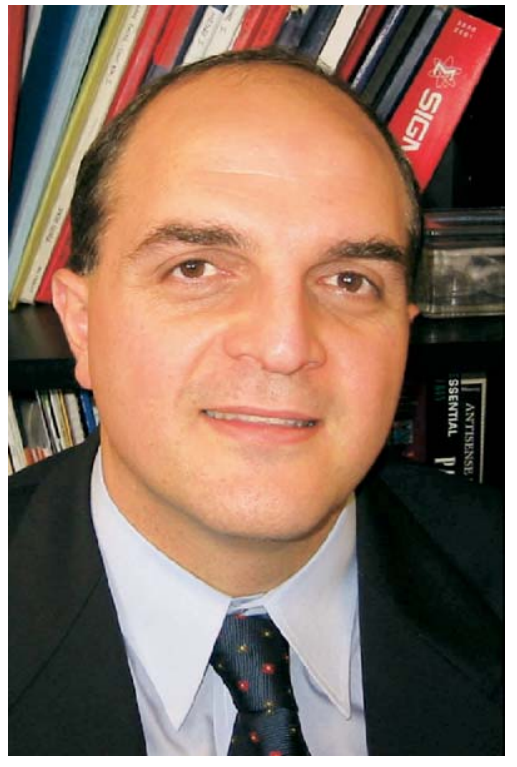

Dr Ascione

Background: Surgical case-mix is seriously worsening, and the results of surgical revascularization on high-risk cohorts should be continuously evaluated. This study investigates the influence of diabetes mellitus on the short and midterm outcome in the modern era of coronary surgery.

Methods and Results: Patients who underwent first-time coronary artery bypass grafting from April 1996 to October 2003 were classified into diabetic and nondiabetic groups. Data were prospectively collected and retrospectively analyzed. A total of 5259 patients were studied, and of these $877(17 \%)$ were diabetic. Patients with diabetes were more likely to be female, have a higher body mass index, be in an advanced New York Heart Association class and Canadian Cardiovascular Society class, have a history of congestive heart failure, have a poor ejection fraction, renal failure, and more extensive coronary artery disease than the nondiabetic group $(P<.001$ for all). In-hospital mortality was $2.2 \%$ and $1 \%$ for diabetic and nondiabetic patients, respectively; however, diabetes was not found to be an independent risk factor for in-hospital mortality (odds ratio $=1.63 ; 95 \%$ confidence interval 0.92-2.88; $P=.089$ ). Postoperative complications were comparable in the two groups, with only renal, neurologic, and gastrointestinal complications significantly associated with diabetes (all $P \leq .05$ ). There was no association between diabetes mellitus and postoperative infective complications. Diabetes remained an independent predictor of 5-year mortality (hazard ratio 1.55 ; 95\% confidence interval 1.22-1.96; $P<.001$ ) and of lower 5-year cardiac-related event-free survival.

Conclusion: Despite a worsening cohort, diabetic patients could be surgically revascularized with low morbidity and mortality, comparable with control patients. The negative effect of diabetes mellitus on the longer-term mortality and morbidity remains a problem.

From the Bristol Heart Institute, Bristol Royal Infirmary, Bristol, United Kingdom. Funded by the British Heart Foundation and Garfield Weston trust.

Received for publication Dec 2, 2005; revisions received May 10, 2006; accepted for publication May 17, 2006.

Address for reprints: R. Ascione, MD, ChM, FRCS, FETCS, Reader in Cardiac Surgery Sciences, Bristol Heart Institute, Bristol Royal Infirmary, Bristol, BS2 8HW, United Kingdom (E-mail: r.ascione@bristol.ac.uk).

J Thorac Cardiovasc Surg 2006;132:802-10

$0022-5223 / \$ 32.00$

Copyright (C) 2006 by The American Association for Thoracic Surgery

doi:10.1016/j.jtcvs.2006.05.056
$\mathrm{D}$ iabetes has been recognized as a major risk factor for atherosclerosis, ${ }^{1,2}$ and its prevalence is on the rise owing to an increasingly aged and obese population. ${ }^{3}$ Currently, patients with diabetes mellitus represent about $20 \%$ of patients undergoing coronary artery bypass graft (CABG) surgery, ${ }^{4-6}$ and in the past diabetes has been associated with increased in-hospital morbidity and mortality. ${ }^{7-9}$ Over the years, reports have maintained the superiority of CABG surgery over percutaneous coronary intervention as the preferred method of coronary revascularization in diabetic patients. ${ }^{10-13}$ In the past decade, however, there has been a significant worsening of the risk profile of surgical patients, ${ }^{14}$ to whom the results of previous studies cannot be uncritically applied. In our own institution, the Parsonnet risk score increased from a median of 4 (interquartile range 2-8) in 1996 to 6 (interquartile range 3-11) in $2002(P<.001)$, the percentage of patients with diabetes has risen from $15 \%$ in 1996 to $20 \%$ of patients treated in 2002, and the surgical population is aging. In 1996, 39\% of patients were over 65 years; by 2002 


$$
\begin{aligned}
& \text { Abbreviations and Acronyms } \\
& \begin{aligned}
\text { CABG } & =\text { coronary artery bypass graft } \\
\text { CI } & =\text { confidence interval } \\
\text { HR } & =\text { hazard ratio } \\
\text { NSTS } & =\text { National Health Service Strategic Tracing } \\
& \text { Service } \\
\text { OPCAB } & \text { off-pump coronary artery bypass } \\
\text { OR } & =\text { odds ratio }
\end{aligned}
\end{aligned}
$$

this had risen to $49 \%$ of patients. Hence, there is a need to update continuously the performance of surgical revascularization in diabetic patients.

The aim of this study was to investigate the effect of diabetes mellitus on in-hospital and midterm clinical outcomes in patients operated on in the current era of CABG surgery.

\section{Methods \\ Patient Selection}

A standard set of perioperative data are collected prospectively for all patients undergoing cardiac surgery at our institution. The data set comprises 5 sections to be filled in consecutively by anesthetist, surgeon, cardiac intensive care unit, high-dependency unit, and ward nurses. Data are entered into the Patient Analysis and Tracking Systems Database (Dentrite Clinical Systems, London, United Kingdom). All adults who underwent first-time CABG surgery at our institution from April 1996 to October 2003 were included. Patients having redo operations, any concomitant surgery, and surgery as a salvage procedure were excluded from the analysis.

\section{Anesthetic and Surgical Management}

Anesthetic and surgical techniques were as reported previously. ${ }^{15}$ For conventional CABG operations, a standard cardiopulmonary bypass circuit was used and systemic temperature was maintained between $34^{\circ} \mathrm{C}$ and $36^{\circ} \mathrm{C}$. Myocardial protection was achieved with intermittent antegrade warm blood cardioplegia. For off-pump coronary artery bypass (OPCAB) procedures, the technique was as previously reported, ${ }^{16}$ and its use was based on surgeon preference. At the end of surgery, patients were transferred to the cardiac intensive care unit and were extubated as soon as they met the following criteria: hemodynamic stability, no excessive bleeding $(<80 \mathrm{~mL} / \mathrm{h})$, normothermia, and consciousness with pain control.

\section{Management of Medication}

Preoperative medications, including antidiabetic agents, statins, $\beta$-blockers, diuretics, antihypertensives, and calcium channel blockers, were routinely omitted on the day of surgery. Aspirin was omitted 3 days before surgery. Angiotensin-converting enzyme inhibitors were withdrawn on the evening before the operation. Aspirin (300 mg) was given 4 hours after the operation if chest tube drainage was less than $100 \mathrm{~mL} / \mathrm{h}$ and decreasing. On the first postoperative day, all patients began receiving enoxaparin (20 $\mathrm{mg}$ ), which was stopped at discharge, and aspirin (300 mg), which was reduced to $75 \mathrm{mg}$ after 3 months. On day 1 , statins, $\beta$-blockers, diuretics, antihypertensives, and angiotensin-converting enzyme inhibitors were all restarted, according to a standard unit protocol, which is based on accurate monitoring of blood pressure and renal function. After discharge, these drugs are prescribed and monitored by the family physician and through routine visits to the cardiology department outpatient clinic.

At our institution we aim to maintain the blood glucose levels in diabetic patients between 5 and $8 \mathrm{mmol} / \mathrm{L}$. Preoperatively, diabetic patients are started on a standard sliding scale insulin infusion, which is maintained for the first 48 hours postoperatively. They are then switched to their baseline antidiabetic medications, which are reviewed by a diabetologist until discharge and managed by the family physician, with regular visit to the diabetes outpatient clinic, after discharge. For nondiabetic patients, the use of sliding scale insulin infusion is triggered by blood glucose levels greater than $10 \mathrm{mmol} / \mathrm{L}$.

\section{Data Collection, Monitoring, Follow-up, and Definitions}

Patients were considered to be diabetic on the basis of history, regardless of duration of disease and need for diabetic medications. Perioperative death was defined as any death occurring in the hospital (ie, in patients who had not been discharged after the operation). In-hospital complications were recorded and defined as previously reported. ${ }^{15,17}$

Information about the vital status was obtained from the National Health Service Strategic Tracing Service (NSTS). Follow-up with respect to cardiac-related events was by a standard questionnaire to the patient and to the patient's family physician, as previously reported. ${ }^{18}$ Nonfatal cardiac-related events included the following: (1) the need for a further coronary revascularization procedure (whether reoperation or percutaneous transluminal coronary angioplasty), (2) patient-reported hospital attendance for myocardial infarction or recurrent angina, or (3) report of cardiacrelated hospital admission by the patient or the family physician. In analyses of patient and cardiac event-free survival, patients who had not experienced an event were censored at the date of last follow-up.

\section{Statistical Analysis}

Baseline and operative characteristics were compared with a $\chi^{2}$ or Fisher exact test (categorical variables) or the Mann-Whitney test (continuous variables). Outcomes for the respective diabetic and nondiabetic subgroups were compared both with and without adjusting for possible confounding, using logistic or Cox regression (Stata version 8.2; Stata Corporation, College Station, Tex), depending on whether the outcome was a binary or a time-to-event variable. Variables included in the adjusted analyses were chosen because they showed imbalance between the two groups and/or they were thought to affect the outcome. The same variables were included in all the risk-adjusted analyses presented (see Table 4 footnote for details). Some potential confounders (eg, age and body mass index) were dichotomized. Model assumptions were checked and, where untenable, alternative models were explored. The number of prognostic variables and outcomes of interest resulted in a large number of statistical comparisons. No correction was made for multiple comparisons, but confidence intervals and 
TABLE 1. Baseline characteristics $(n=5259)$

\begin{tabular}{|c|c|c|c|c|c|}
\hline Variable & Diabetic $(\mathbf{n}=877)$ & $\%(16.7)$ & Nondiabetic ( $n=4382)$ & $\%(83.3)$ & $P$ value \\
\hline Age (y) & $64(57-70)$ & & $64(58-70)$ & & .66 \\
\hline Body mass index $\left(\mathrm{m}^{2}\right)$ & $27.5(25.3-31.1)$ & & $27.0(24.7-29.4)$ & & $<.001$ \\
\hline Female sex & 221 & (25.2) & 795 & (18.1) & $<.001$ \\
\hline \multicolumn{6}{|l|}{ Dyspnea class } \\
\hline NYHA I and II & 485 & (55.3) & 2933 & (66.9) & $<.001$ \\
\hline NYHA III and IV & 392 & (44.7) & 1449 & (33.1) & \\
\hline \multicolumn{6}{|l|}{ Canadian Cardiovascular } \\
\hline \multicolumn{6}{|l|}{ Score } \\
\hline $\operatorname{CCS} 0$ & 25 & (2.9) & 72 & (1.6) & $<.001$ \\
\hline $\operatorname{CCS} 1-2$ & 266 & (30.3) & 1664 & $(38.0)$ & \\
\hline CCS 3-4 & 586 & (66.8) & 2646 & (60.4) & \\
\hline Congestive heart failure & 150 & (17.1) & 418 & $(9.5)$ & $<.001$ \\
\hline Previous myocardial infarction & 410 & $(46.8)$ & 1866 & $(42.6)$ & .023 \\
\hline Hypertension & 615 & (70.2) & 2434 & $(55.6)$ & $<.001$ \\
\hline Hypercholestrolemic & 659 & (75.1) & 3291 & (75.4) & .87 \\
\hline Current smoker & 83 & (9.5) & 569 & $(13.0)$ & .015 \\
\hline Renal failure & 33 & (3.8) & 81 & $(1.9)$ & $<.001$ \\
\hline Arrhythmia & 52 & (5.9) & 178 & (4.1) & .014 \\
\hline Left main stem $>50 \%$ stenosis & 104 & $(14.6)$ & 582 & (16.1) & .30 \\
\hline \multicolumn{6}{|l|}{ Extent of coronary disease } \\
\hline $1-2$ vessel & 217 & (25.1) & 1440 & (33.4) & $<.001$ \\
\hline 3 vessel & 649 & (75.0) & 2870 & (66.6) & \\
\hline \multicolumn{6}{|l|}{ Ejection fraction } \\
\hline$>50 \%$ & 575 & (65.9) & 3155 & (72.3) & $<.001$ \\
\hline $30 \%-50 \%$ & 225 & (25.8) & 1006 & $(23.0)$ & \\
\hline$<30 \%$ & 72 & (8.3) & 207 & (4.7) & \\
\hline Urgent operation & 399 & (45.7) & 1844 & $(42.2)$ & .057 \\
\hline
\end{tabular}

NYHA, New York Heart Association; CCS, Canadian Cardiovascular Society.

exact $P$ values are presented throughout. The interpretation of the findings takes into account the consistency of the findings and their magnitude, as well as their statistical significance.

\section{Results}

Data on 5259 consecutive patients undergoing first-time CABG surgery were collected prospectively. Of these, 877 $(17 \%)$ were treated diabetics. The distribution of baseline characteristics between the two groups is shown in Table 1. Diabetic patients were more likely to be female, have a higher body mass index, be in an advanced NYHA and CCS class, have a history of congestive heart failure and myocardial infarction, be hypertensive, have an ejection fraction less than 50\%, and have more extensive coronary artery disease than the nondiabetic patients (all $P<.001$ ).

The distribution of operative variables and postoperative outcomes is shown in Table 2. Similar percentages of patients in the two groups were revascularized without the use of cardiopulmonary bypass and underwent complete coronary revascularization (33.5\% vs $31.3 \%$ and $75.9 \%$ vs $80.4 \%$, diabetic vs nondiabetic patients, respectively). At our institution, 4 consultants perform OPCAB surgery. Overall, the use of OPCAB surgery among these 4 surgeons ranged from
$26 \%$ to $89 \%$, but in the more recent era (2000 onward) all carried out $70 \%$ or more of their operations off-pump. Neither the distribution of coronary disease nor the diabetic status is a factor that influences the decision to use OPCAB surgery.

The observed in-hospital mortality rate was $2.3 \%$ and $1 \%$ in the diabetic and nondiabetic groups, respectively. The incidence of in-hospital neurologic complications was $4.8 \%$ and $2.2 \%$ and that of infective complications was $4 \%$ and $2.6 \%$ in the diabetic and nondiabetic patients, respectively. This included infections of the sternum, conduit donor site, and episodes of septicemia (source known or unknown).

Table 3 shows the risk factors for in-hospital mortality. The presence of diabetes mellitus was not found to be an independent predictor of in-hospital mortality on multivariate analysis $(P=.089)$. On the contrary, age older than 65 years, female sex, history of congestive heart failure, renal failure, ejection fraction less than $50 \%$, left main stem disease, and urgent operation were independent predictors of in-hospital death.

Overall, OPCAB surgery had no significant association with in-hospital mortality (odds ratio $[\mathrm{OR}]=0.99$; 
TABLE 2. Operative and postoperative outcomes

\begin{tabular}{|c|c|c|c|c|}
\hline Variable & Diabetic $(n=877)$ & $\%(16.7)$ & Nondiabetic $(\mathrm{n}=4382)$ & $\%(83.3)$ \\
\hline In-hospital deaths & 19 & $(2.2)$ & 45 & $(1.0)$ \\
\hline Off-pump & 294 & $(33.5)$ & 1370 & (31.3) \\
\hline Distal anastomosis (mean \pm SD) & $2.8( \pm 0.8)$ & & $2.7( \pm 0.9)$ & \\
\hline Complete revascularization & 666 & $(75.9)$ & 3521 & $(80.4)$ \\
\hline Use of left internal thoracic artery & 781 & (89.1) & 4022 & (91.8) \\
\hline Use of a second arterial conduit & 151 & $(17.2)$ & 1043 & $(23.8)$ \\
\hline Perioperative myocardial infarction & 20 & $(2.3)$ & 94 & $(2.2)$ \\
\hline Postoperative atrial fibrillation & 135 & $(15.4)$ & 571 & $(13.0)$ \\
\hline Pulmonary complications & 124 & $(14.1)$ & 544 & (12.4) \\
\hline Chest infection & 44 & $(5.1)$ & 228 & $(5.2)$ \\
\hline Neurologic complications & 42 & (4.8) & 94 & (2.2) \\
\hline Infective complications & 35 & $(4.0)$ & 115 & (2.6) \\
\hline Major infection of sternum requiring rewiring & 8 & (1.0) & 31 & $(0.7)$ \\
\hline Minor infection of sternum & 5 & $(0.6)$ & 22 & (0.5) \\
\hline Leg wound infection & 6 & $(0.7)$ & 20 & $(0.5)$ \\
\hline Septicemia (source any/unknown) & 14 & (1.6) & 48 & (1.1) \\
\hline Other infections & 3 & $(0.3)$ & 6 & $(0.1)$ \\
\hline Renal complications & 54 & $(6.2)$ & 143 & (3.3) \\
\hline Gastrointestinal complications & 18 & (2.1) & 43 & (1.0) \\
\hline Multisystem failure & 11 & (1.3) & 27 & $(0.6)$ \\
\hline Reoperation for bleeding/tamponade & 26 & (3.0) & 167 & (3.8) \\
\hline \multicolumn{5}{|l|}{ Blood transfusion* } \\
\hline Patients & 327 & $(37.3)$ & 1509 & $(34.4)$ \\
\hline Units & $2(1-3)$ & & $2(1-3)$ & \\
\hline \multicolumn{5}{|l|}{ Fresh frozen plasma* } \\
\hline Patients & 61 & (7.0) & 410 & (9.4) \\
\hline Units & $4(2-4)$ & & $4(2-4)$ & \\
\hline \multicolumn{5}{|l|}{ Platelets* } \\
\hline Patients & 90 & $(10.3)$ & 555 & $(12.7)$ \\
\hline Units & $1(1-2)$ & & $1(1-2)$ & \\
\hline ITU stay $(d)$ & $1(1-2)$ & & $1(1-1)$ & \\
\hline Postop stay (d) & $7(6-9)$ & & $6(5-8)$ & \\
\hline
\end{tabular}

$S D$, Standard deviation; ITU, intensive treatment unit. *Transfusion details not recorded before April 1997 (n $=4520$, 768 diabetic and 3752 nondiabetic patients).

95\% confidence interval $[\mathrm{CI}] 0.56-1.71 ; P=.96)$ on multivariate analysis, and there was no evidence to suggest that the impact of OPCAB surgery on in-hospital mortality differed between diabetic and nondiabetic patients $(P=.41)$.

Table 4 shows the effect of diabetes on nonfatal outcomes. After adjustment for differences in prognostic variables, diabetic patients had a significantly higher chance of having neurologic, renal, and gastrointestinal complications after CABG surgery. OPCAB surgery was found to be associated with fewer neurologic complications $(\mathrm{OR}=0.58$; 95\% CI $0.38-0.89 ; P=.012$ ), but not renal complications $(P=.18)$ or gastrointestinal complications $(P=.82)$ on multivariate analysis. For all in-hospital outcomes, including mortality, the outcome for patients with insulin-dependent diabetes was similar to that for diabetic patients not dependent on insulin $(P \geq .17)$.

\section{Midterm Clinical Outcomes}

Overall, $99 \%$ of the study cohort was successfully matched to the NSTS database. The remaining patients were censored at hospital discharge. Median follow-up was 3 years in both groups. Diabetic patients had a significantly lower 5 -year survival than did nondiabetic patients (adjusted hazard ratio $[\mathrm{HR}]=1.55 ; 95 \% \mathrm{CI} 1.22-1.96 ; P<.001$ ) (Figure 1). Other patient factors identified as independent predictors of 5-year all-cause mortality were advanced age ( $>65$ years), renal failure, preoperative arrhythmias, ejection fraction less than $50 \%$, left main stem disease, advanced Canadian Cardiovascular Society class, the presence of congestive heart failure, and smoking less than 1 month before surgery $(P \leq .032)$.

Follow-up data were available for $80 \%$ of eligible patients. Of the remaining $20 \%, 1 \%$ have indicated that they are unable or unwilling to participate, $4.7 \%$ have since died, 
TABLE 3. Predictors of in-hospital mortality

\begin{tabular}{|c|c|c|c|c|}
\hline \multirow[b]{2}{*}{ Variable } & \multicolumn{2}{|c|}{ Univariate } & \multicolumn{2}{|c|}{ Multivariate } \\
\hline & OR $(95 \% \mathrm{Cl})$ & $P$ value & OR $(95 \% \mathrm{Cl})$ & $P$ value \\
\hline Age $>65$ y & $2.56(1.51-4.32)$ & $<.001$ & $1.69(0.97-2.94)$ & .060 \\
\hline Diabetes & $2.13(1.24-3.67)$ & .006 & $1.63(0.92-2.88)$ & .089 \\
\hline NYHA III and IV & $2.94(1.78-4.87)$ & $<.001$ & $1.50(0.85-2.64)$ & .159 \\
\hline CCS 3 and 4 & $2.48(1.34-4.58)$ & .004 & $1.20(0.61-2.35)$ & .590 \\
\hline Current smoker & $1.24(0.68-2.25)$ & .477 & $1.56(0.82-2.94)$ & .171 \\
\hline Previous myocardial infarction & $1.32(0.80-2.15)$ & .276 & $0.82(0.48-1.42)$ & .488 \\
\hline Renal failure & $4.87(2.06-11.5)$ & $<.001$ & $2.61(1.05-6.49)$ & .038 \\
\hline Arrhythmia & $2.74(1.23-6.07)$ & .013 & $1.66(0.71-3.83)$ & .238 \\
\hline Ejection fraction $<50 \%$ & $3.70(2.24-6.11)$ & $<.001$ & $2.55(1.43-4.53)$ & .001 \\
\hline Urgent & $3.00(1.76-5.10)$ & $<.001$ & $1.85(1.05-3.27)$ & .034 \\
\hline Off-pump surgery & $1.06(0.62-1.78)$ & .839 & $0.99(0.56-1.71)$ & .959 \\
\hline
\end{tabular}

OR, Odds ratio; $\mathrm{Cl}$, confidence interval; BMI, body mass index; NYHA, New York Heart Association; CCS, Canadian Cardiovascular Society.

and the remainder remain lost to follow-up. The cumulative incidence of one or more cardiac-related events is shown in Figure 2. The cumulative incidence was similar at 1 year for both nondiabetic and diabetic patients $(8.6 \%$ and $7.0 \%$, respectively). Thereafter, the curves separate with a marked increase in incidence in the diabetic group between years 1 and 2 postoperatively. The cumulative incidence at 2 years was $15.0 \%$ (95\% CI $13.8 \%-16.3 \%$ ) and $21.8 \%$ (95\% CI $18.7 \%-25.3 \%$ ) in nondiabetic and diabetic patients, respectively; subsequently the curves follow an almost parallel course. At 5 years, $48 \%$ of diabetic patients versus $60 \%$ of

TABLE 4. The effect of diabetes on clinical outcomes

\begin{tabular}{lccr}
\hline & \multicolumn{3}{c}{ Adjusted* effect size } \\
\cline { 2 - 4 } Outcome & OR & $\mathbf{9 5 \%}$ Cl & P value \\
\hline In-hospital death & 1.63 & $0.92-2.88$ & .089 \\
Myocardial infarction & 1.03 & $0.63-1.70$ & .899 \\
Atrial fibrillation & 1.10 & $0.89-1.37$ & .360 \\
Chest infection & 0.91 & $0.65-1.28$ & .602 \\
Neurologic complications & 2.01 & $1.37-2.96$ & $<.001$ \\
Infective complications & 1.27 & $0.85-1.91$ & .238 \\
Renal complications & 1.63 & $1.17-2.29$ & .004 \\
Gastrointestinal & 1.76 & $0.99-3.12$ & .054 \\
$\quad$ complications & & & \\
Multisystem failure & 1.56 & $0.75-3.23$ & .234 \\
\hline
\end{tabular}

$O R$, Odds ratio; $\mathrm{Cl}$, confidence interval. *Adjusted for age, sex, body mass index, New York Heart Association status, Canadian Cardiovascular Society group, history of congestive heart failure, smoking status, preoperative myocardial infarction, renal failure, arrhythmias, left main stem disease, ejection fraction, urgent operation, hypertension, extent of coronary disease, and off-pump surgery. nondiabetic patients were free of any cardiac-related event. The incidence of one or more cardiac-related events over time was significantly higher for patients with diabetes, both on univariate analysis $(\mathrm{HR}=1.44 ; 95 \%$ CI 1.26-1.64; $P<.001$ ) and on multivariate modeling (adjusted HR = $1.24 ; 95 \%$ CI 1.08-1.42; $P=.002$ ). However, the incidence of patient-reported hospital attendance for myocardial infarction, congestive heart failure, and/or further coronary revascularization (main adverse coronary events) was similar at 5 years, when $5.9 \%$ (95\% CI $4.9 \%-6.9 \%$ ) of nondiabetic patients had experienced one or more main adverse coronary events compared with $6.9 \%$ (95\% CI $4.8 \%-10.0 \%)$ of diabetic patients (unadjusted $P=.23$; adjusted $P=.76$ ).

\section{Discussion}

There are several main findings from this study. The inhospital mortality in the diabetic patients was low (2.2\%). Diabetes mellitus was not an independent predictor of inhospital mortality. The presence of diabetes mellitus was a strong independent risk factor for neurologic and renal complications, but not for infective complications. Diabetes was associated with a significantly higher incidence of late mortality and cardiac-related events.

The in-hospital mortality in our study for diabetic patients compared favorably with the literature, despite the worsening of case-mix in the current surgical era (over the period of this study the median Parsonnet risk score increased from 4 to 6 and the numbers of older patients and of diabetic patients treated increased). Thourani and associates ${ }^{9}$ reported on 2278 diabetic patients who underwent CABG surgery from 1978 to 1993 with an observed mor- 


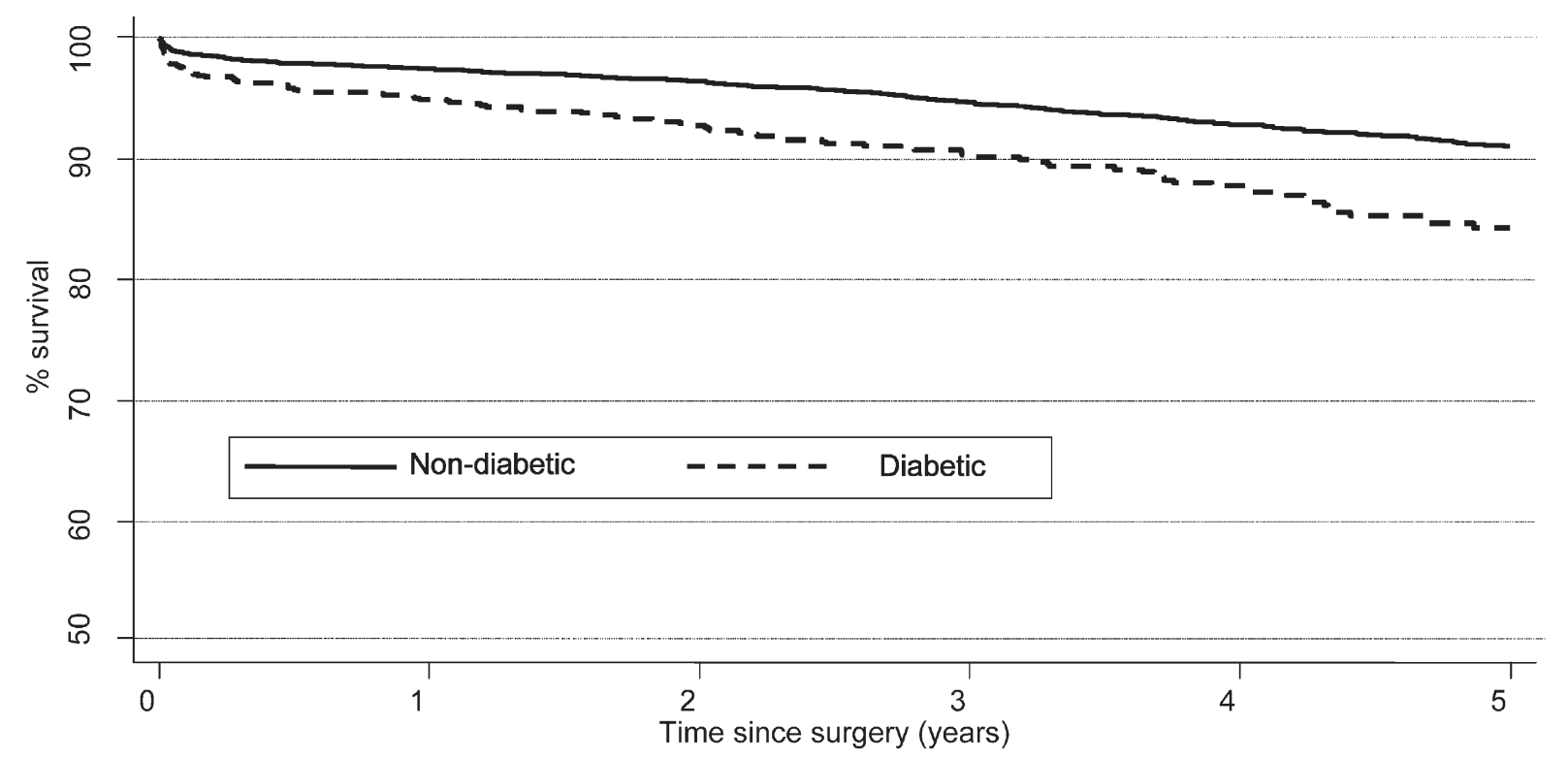

\begin{tabular}{|c|c|c|c|c|c|}
\hline & 1 year & 2 years & 3 years & 4 years & 5 years \\
\hline \multicolumn{6}{|l|}{ Non diabetics } \\
\hline $\mathrm{N}$ remaining & 4040 & 3451 & 2765 & 2077 & 1446 \\
\hline Deaths per year & 107 & 41 & 55 & 49 & 33 \\
\hline$\%$ survival & 97.5 & 96.5 & 94.8 & 92.9 & 91.1 \\
\hline$(95 \% \mathrm{Cl})$ & $(97.0$ to 98.0$)$ & (95.8 to 97.0$)$ & (94.0 to 95.4$)$ & (91.9 to 93.7 ) & (90.0 to 92.1$)$ \\
\hline \multicolumn{6}{|l|}{ Diabetics } \\
\hline $\mathrm{N}$ remaining & 780 & 638 & 484 & 345 & 224 \\
\hline Deaths per year & 43 & 16 & 15 & 12 & 12 \\
\hline$\%$ survival & 95.0 & 92.9 & 90.5 & 87.9 & 84.4 \\
\hline$(95 \% \mathrm{Cl})$ & (93.3 to 96.3$)$ & (90.9 to 94.4 ) & (88.1 to 92.4$)$ & (85.1 to 90.2 ) & (78.3 to 85.6$)$ \\
\hline
\end{tabular}

Figure 1. Kaplan-Meier survival to 5 years by diabetic status.

tality of $3.9 \%$ and found diabetes to be an independent predictor of in-hospital mortality. Several other studies in the late 1980s had similar findings, reporting mortality rates as high as 5\%., 7,8 North American multicenter registry data on 41,663 diabetic patients who underwent CABG surgery in 1997 reported a 30-day mortality of $3.7 \% .^{6}$ Two recent studies by Szabo, ${ }^{19} \mathrm{Kubal}^{20}$ and their associates (similar to our study period) agreed with our findings, reporting mortalities of $2.6 \%$ and $2.4 \%$ for their diabetic populations, respectively. The older series are not contemporary with respect to internal thoracic artery use, which was less than $50 \%$, and modern perfusion and anesthetic techniques. The North American series did not specify blood glucose management in the perioperative period, which is now recognized to lead to a better outcome. ${ }^{21}$ In contrast, this study and both contemporary series mentioned previously had a strict postoperative glucose management protocol. Over 30\% of our patients in both groups underwent revascularization without the use of cardiopulmonary bypass. The use of OPCAB surgery was based on surgeon preference, and it did not depend on either the preoperative diabetic status or the distribution of coronary disease. OPCAB surgery was associated with fewer neurologic complications $(P=.012)$ but did not affect the incidence of renal complications $(P=$ .18). Magee and colleagues ${ }^{22}$ compared diabetic and nondiabetic patients who underwent OPCAB surgery and showed a lower observed mortality for diabetic patients and an even lower observed mortality for nondiabetic patients compared with the on-pump group, although this did not translate as a significant benefit for diabetic patients after risk adjustment. Similarly, Kubal and colleagues ${ }^{20}$ used OPCAB surgical technique in $21.7 \%$ of diabetic patients and had the lowest reported mortality rate of $2.4 \%$ for a diabetic series to date.

After adjustment for differences in risk profile between diabetic and nondiabetic patients, renal, neurologic and gastrointestinal complications showed significant effect sizes. These risks might be minimized by more thoughtful management, for example, with specific attention to preoperative noninvasive vascular evaluation of carotid and renal arteries, 


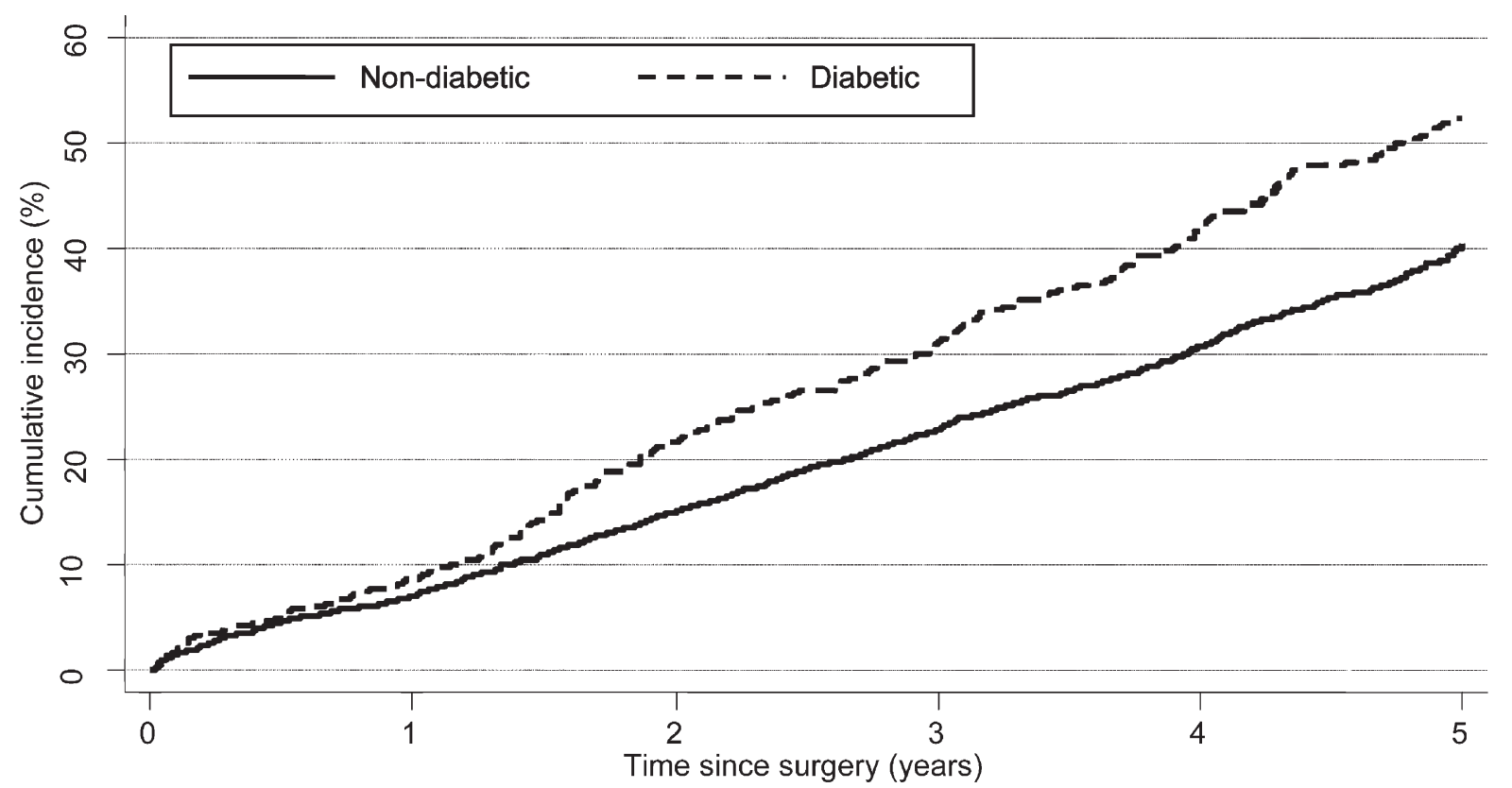

\begin{tabular}{|c|c|c|c|c|c|}
\hline & 1 year & 2 years & 3 years & 4 years & 5 years \\
\hline \multicolumn{6}{|l|}{ Non diabetics } \\
\hline $\mathrm{N}$ remaining & 3177 & 2493 & 1979 & 1500 & 1037 \\
\hline First event per year & 243 & 253 & 214 & 185 & 187 \\
\hline Cum. incidence (\%) & 7.0 & 15.0 & 22.8 & 30.7 & 40.4 \\
\hline$(95 \% \mathrm{Cl})$ & $(6.2$ to 7.9$)$ & (13.8 to 16.3 ) & (21.3 to 24.3 ) & ( 29.0 to 32.4 ) & (38.4 to 42.4 ) \\
\hline \multicolumn{6}{|l|}{ Diabetics } \\
\hline $\mathrm{N}$ remaining & 593 & 432 & 325 & 237 & 157 \\
\hline First event per year & 56 & 79 & 47 & 46 & 39 \\
\hline Cum. incidence (\%) & 8.6 & 21.8 & 31.0 & 41.6 & 52.3 \\
\hline$(95 \% \mathrm{Cl})$ & (6.7 to 11.0$)$ & (18.7 to 25.3 ) & (27.3 to 34.9$)$ & (37.4 to 46.0$)$ & $(47.7$ to 57.0$)$ \\
\hline
\end{tabular}

Figure 2. Five-year cumulative incidence of cardiac-related events on follow-up.

elimination or minimization of intraoperative aortic manipulation, preoperative volume replacement, and the timing of angiotensin-converting enzyme inhibitor therapy in patients with preoperative renal insufficiency.

Previous reports in the literature generally report an increased short-term mortality and morbidity in CABG patients, which includes cardiovascular, infective, and respiratory complications. ${ }^{6,9,20}$ Whereas in our study the probability of an increased risk of in-hospital death for patients with diabetes mellitus was greater than .05 , a $63 \%$ increased risk was observed, which could occur by chance in around $10 \%$ of studies $(P=.092)$. The $95 \% \mathrm{CI}$ further suggests that the true in-hospital mortality risk could be as much as $187 \%$ higher for a diabetic compared with a nondiabetic patient. With a $17 \%$ prevalence of diabetes in our population and a low $1 \%$ in-hospital mortality rate among nondiabetic patients, a study of more than 16,000 patients would be needed to identify a $63 \%$ rise in mortality risk for persons with diabetes as statistically significant with $80 \%$ power.
The predisposition of diabetic patients to infective complications after cardiac surgery has been often suggested., ${ }^{6,23-27}$ We did not find an independent association between diabetes and infective complications $(\mathrm{OR}=1.27$; $95 \%$ CI 0.85 $1.91 ; P=.24)$. Angiopathy, neuropathy, and hyperglycemia associated with diabetes are identified as the main reasons for predisposition to infections. ${ }^{28}$ Impaired host defense mechanisms such as impaired wound healing, impaired granulocyte function, decreased cellular immunity, impaired complement function, and decreased lymphokine response may be influenced by glycemic control. ${ }^{28-30}$ Our results might be due to the active control of blood glucose in diabetic patients with insulin infusion during the early postoperative period. Others have suggested that this reduces mortality and complications. ${ }^{21,26,31,32}$ Controlling blood glucose levels at less than $11.1 \mathrm{mmol} / \mathrm{L}(200 \mathrm{mg} / \mathrm{dL})$ in diabetic patients leads to significantly fewer postoperative complications, including in-hospital death. ${ }^{24,25,33}$ Furthermore, Fish and associates $^{25}$ found that, in diabetic patients, a blood glucose 
level less than $11.1 \mathrm{mmol} / \mathrm{L}$ carried a $36 \%$ higher risk and a blood glucose level of $13.9 \mathrm{mmol} / \mathrm{L}$ or more carried a $63 \%$ higher risk of infective complications.

Diabetes was found to be an independent predictor of 5-year mortality and lower cardiac event-free survival, despite key patient risk factors, including diabetes, hypertension, and hypercholesterolemia being managed in the longterm by the family physician and cardiologist. However, we cannot provide data on the long-term management of other factors that could potentially influence late mortality and cardiac event-free survival, such as obesity and lack of exercise. This finding is in keeping with the other reports in the literature. ${ }^{6,9,19,34-36}$ The negative impact of diabetes mellitus on long-term outcome is probably influenced by several factors. First are the end-organ effects of diabetes and the influence of the insulin-resistant syndrome on the progression of comorbidities. Second is the presence of more complex diffuse coronary artery disease. Third is the rapid progression of coronary artery disease and occurrence of new atherosclerotic lesions in the native vessels in diabetic patients with insulin-resistant syndrome. Fourth, type-2 diabetes mellitus in particular affects the morphology of the bypass conduits and may be a factor in late conduit failure. Similar to our study on follow-up, Thourani and associates 9 found no difference in the incidence of myocardial infarction and need for reintervention up to 10 years after CABG.

Historically, surgery has been considered the treatment of choice for diabetic patients with multivessel coronary disease. ${ }^{5}$ More recently, there has been the advent of drugeluting stents, and several trials are ongoing to assess the impact of this technique for diabetic patients. ${ }^{37}$

The limitation of this study is that it was a retrospective analysis, although the data were collected prospectively. At the time of data collection, this analysis had not been planned. It is possible that the differences or similarities observed between the groups were a result of unforeseen confounders. However, multivariate analysis is a theoretically sound statistical method of accounting for differences between groups in the absence of random allocation. Also, this study was based on a large cohort of patients from a single institution, which adds to the power of these results.

In conclusion, despite the worsening case-mix, the early mortality and morbidity of diabetic patients undergoing CABG surgery has significantly improved and is comparable with those of nondiabetic patients. These improvements could be due to modern surgical, anesthetic, and cardopulmonary techniques, as well as to postoperative blood glucose management strategies.

\section{References}

1. Beckman JA, Creager MA, Libby P. Diabetes and atherosclerosis: epidemiology, pathophysiology, and management. JAMA. 2002;287: 2570-81.
2. Creager MA, Luscher TF, Cosentino F, Beckman JA. Diabetes and vascular disease: pathophysiology, clinical consequences, and medical therapy: Part I. Circulation. 2003;108:1527-32.

3. Diabetes UK. Diabetes in the UK 2004: report from Diabetes UK; 2004. October 2004.

4. Cohen Y, Raz I, Merin G, Mozes B. Comparison of factors associated with 30-day mortality after coronary artery bypass grafting in patients with versus without diabetes mellitus. Israeli Coronary Artery Bypass (ISCAB) Study Consortium. Am J Cardiol. 1998;81:7-11.

5. Flaherty JD, Davidson CJ. Diabetes and coronary revascularization. JAMA. 2005;293:1501-8.

6. Carson JL, Scholz PM, Chen AY, Peterson ED, Gold J, Schneider SH. Diabetes mellitus increases short-term mortality and morbidity in patients undergoing coronary artery bypass graft surgery. $J$ Am Coll Cardiol. 2002;40:418-23.

7. Adler DS, Goldman L, O'Neil A, Cook EF, Mudge GH Jr, Shemin RJ, et al. Long-term survival of more than 2,000 patients after coronary artery bypass grafting. Am J Cardiol. 1986;58:195-202.

8. Morris JJ, Smith LR, Jones RH, Glower DD, Morris PB, Muhlbaier LH, et al. Influence of diabetes and mammary artery grafting on survival after coronary bypass. Circulation. 1991;84(5 Suppl):III275-84.

9. Thourani VH, Weintraub WS, Stein B, Gebhart SS, Craver JM, Jones EL, et al. Influence of diabetes mellitus on early and late outcome after coronary artery bypass grafting. Ann Thorac Surg. 1999;67:1045-52.

10. Comparison of coronary bypass surgery with angioplasty in patients with multivessel disease. The Bypass Angioplasty Revascularization Investigation (BARI) Investigators. N Engl J Med. 1996;335:217-25.

11. Seven-year outcome in the Bypass Angioplasty Revascularization Investigation (BARI) by treatment and diabetic status. $\mathrm{J} \mathrm{Am} \mathrm{Coll}$ Cardiol. 2000;35:1122-9.

12. Abizaid A, Costa MA, Centemero M, Abizaid AS, Legrand VM, Limet RV, et al. Clinical and economic impact of diabetes mellitus on percutaneous and surgical treatment of multivessel coronary disease patients: insights from the Arterial Revascularization Therapy Study (ARTS) trial. Circulation. 2001;104:533-8.

13. Legrand VM, Serruys PW, Unger F, van Hout BA, Vrolix MC, Fransen GM, et al. Three-year outcome after coronary stenting versus bypass surgery for the treatment of multivessel disease. Circulation. 2004; 109:1114-20.

14. Ferguson TB Jr, Hammill BG, Peterson ED, DeLong ER, Grover FL, STS National Database Committee. A decade of change-risk profiles and outcomes for isolated coronary artery bypass grafting procedures, 1990-1999: a report from the STS National Database Committee and the Duke Clinical Research Institute. Ann Thorac Surg. 2002;73: 480-9.

15. Ascione R, Caputo M, Calori G, Lloyd CT, Underwood MJ, Angelini GD. Predictors of atrial fibrillation after conventional and beating heart coronary surgery: a prospective, randomized study. Circulation. 2000; 102:1530-5.

16. Watters MP, Ascione R, Ryder IG, Ciulli F, Pitsis AA, Angelini GD. Haemodynamic changes during beating heart coronary surgery with the "Bristol Technique." Eur J Cardiothorac Surg. 2001;19:34-40.

17. Ascione R, Reeves BC, Rees K, Angelini GD. Effectiveness of coronary artery bypass grafting with or without cardiopulmonary bypass in overweight patients. Circulation. 2002;106:1764-70.

18. Taylor F, Reeves B, Ascione R, Angelini G. Accuracy of reporting cardiac related events during long term follow up. Heart. 2003;89: $331-2$.

19. Szabo Z, Hakanson E, Svedjeholm R. Early postoperative outcome and medium-term survival in 540 diabetic and 2239 nondiabetic patients undergoing coronary artery bypass grafting. Ann Thorac Surg. 2002;74:712-9.

20. Kubal C, Srinivasan AK, Grayson AD, Fabri BM, Chalmers JAC. Effect of risk-adjusted diabetes on mortality and morbidity after coronary artery bypass surgery. Ann Thorac Surg. 2005;79:1570-6.

21. Lazar HL, Chipkin SR, Fitzgerald CA, Bao Y, Cabral H, Apstein CS. Tight glycemic control in diabetic coronary artery bypass graft patients improves perioperative outcomes and decreases recurrent ischemic events. Circulation. 2004;109:1497-502.

22. Magee MJ, Dewey TM, Acuff T, Edgerton JR, Hebeler JF, Prince SL, et al. Influence of diabetes on mortality and morbidity: off-pump 
coronary artery bypass grafting versus coronary artery bypass grafting with cardiopulmonary bypass. Ann Thorac Surg. 2001;72:776-80; discussion 780-1.

23. Crabtree TD, Codd JE, Fraser VJ, Bailey MS, Olsen MA, Damiano RJ Jr. Multivariate analysis of risk factors for deep and superficial sternal infection after coronary artery bypass grafting at a tertiary care medical center. Semin Thorac Cardiovasc Surg. 2004;16:53-61.

24. Estrada CA, Young JA, Wiley NL, Chitwood WR Jr. Outcomes and perioperative hyperglycemia in patients with or without diabetes mellitus undergoing coronary artery bypass grafting. Ann Thorac Surg. 2003;75:1392-9

25. Fish LH, Weaver TW, Moore AL, Steel LG. Value of postoperative blood glucose in predicting complications and length of stay after coronary artery bypass grafting. Am J Cardiol. 2003;92:74-6.

26. Golden SH, Peart-Vigilance C, Kao WH, Brancati FL. Perioperative glycemic control and the risk of infectious complications in a cohort of adults with diabetes. Diabetes Care. 1999;22:1408-14.

27. Guvener M, Pasaoglu I, Demircin M, Oc M. Perioperative hyperglycemia is a strong correlate of postoperative infection in type II diabetic patients after coronary artery bypass grafting. Endocr J. 2002;49: 531-7.

28. Murphy DP, Tan JS, File TM Jr. Infectious complications in diabetic patients. Prim Care. 1981;8:695-714.

29. McMahon MM, Bistrian BR. Host defenses and susceptibility to infection in patients with diabetes mellitus. Infect Dis Clin North Am. 1995;9:1-9

30. Leibovici L, Yehezkelli Y, Porter A, Regev A, Krauze I, Harell D. Influence of diabetes mellitus and glycaemic control on the characteristics and outcome of common infections. Diabet Med. 1996;13:457-63.

31. Eagle KA, Guyton RA, Davidoff R, Ewy GA, Fonger J, Gardner TJ, et al. ACC/AHA guidelines for coronary artery bypass graft surgery: executive summary and recommendations: A report of the American
College of Cardiology/American Heart Association Task Force on Practice Guidelines (committee to revise the 1991 guidelines for coronary artery bypass graft surgery). Circulation. 1999;100:1464-80.

32. Eagle KA, Guyton RA, Davidoff R, Ewy GA, Fonger J, Gardner TJ, et al. ACC/AHA guidelines for coronary artery bypass graft surgery: a report of the American College of Cardiology/American Heart Association Task Force on Practice Guidelines (committee to revise the 1991 guidelines for coronary artery bypass graft surgery). American College of Cardiology/American Heart Association. J Am Coll Cardiol. 1999;34:1262-347.

33. Furnary AP, Wu Y, Bookin SO. Effect of hyperglycemia and continuous intravenous insulin infusions on outcomes of cardiac surgical procedures: the Portland Diabetic Project. Endocr Pract. 2004; 10(Suppl 2):21-33.

34. Brener SJ, Lytle BW, Casserly IP, Schneider JP, Topol EJ, Lauer MS Propensity analysis of long-term survival after surgical or percutaneous revascularization in patients with multivessel coronary artery disease and high-risk features. Circulation. 2004;109:2290-5.

35. Herlitz J, Brandrup-Wognsen G, Haglid M, Karlson BW, Hartford M, Karlsson T. Predictors of death during 5 years after coronary artery bypass grafting. Int J Cardiol. 1998;64:15-23.

36. Whang W, Bigger JT Jr. Diabetes and outcomes of coronary artery bypass graft surgery in patients with severe left ventricular dysfunction: results from The CABG Patch Trial database. The CABG Patch Trial Investigators and Coordinators. J Am Coll Cardiol. 2000;36: 1166-72.

37. Serruys PW, Lemos PA, van Hout BA, Arterial Revascularisation Therapies Study part II Steering Committee and Investigators. Sirolimus eluting stent implantation for patients with multivessel disease: rationale for the Arterial Revascularisation Therapies Study part II (ARTS II). Heart. 2004;90:995-8. 